\title{
Car ownership and commuting mode of the "original" residents in a high-density city center: A case study in Shanghai
}

\author{
Tao Chen \\ Department of Urban Planning \\ Tongji University \\ chent.10b@igsnrr.ac.cn \\ Yanbo Ge \\ University of Washington
}

\author{
Haixiao Pan (corresponding author) \\ Key Laboratory of Ecology and Energy-Saving \\ Study of Dense Habitat \\ Department of Urban Planning \\ Tongji University \\ hxpank@online.sh.cn
}

\begin{abstract}
As a result of rapid urbanization and motorization in China, numerous mega-cities have emerged, and large numbers of people live and work in the city centers. Consequently, developing a public transport-oriented urban structure and promoting sustainable development are major planning strategies for the country. To understand the impact of rail transit on motorization in a high-density city center, we conduct a household travel survey in three neighborhoods around metro stations in the central area of Shanghai. We examine the car buying and commuting behavior of those Shanghai "original" residents who lived there when the city began growing, engulfing them in the center.

Studies have shown that $40 \%$ of commuters in the city center commute outward, following a virtually reversed commute pattern, and the factors significantly affecting their car purchasing choice include their attitude toward cars and transit, household incomes, ownership of the apartments they live in, and the distance between family members' workplaces and nearest metro stations. Despite easy access to the metro from their home in the city center, those who purchase their apartment units also likely own a car, while those who rent their apartment units are less likely to own a car; however, these odds are still higher than for those who live in an apartment unit inherited from their relatives or provided by their company. In the city center, if a family owns a car, then that car would almost certainly be used for daily commuting.

A multinomial logistic model is applied to examine the factors influencing the tendency for using cars. The results show that people's choices of commuting by alternative modes rather than cars are also shaped by their attitude toward public transportation, but other factors can also subtly change people's commuting behavior under certain conditions. The commuting distance discourages people from walking and taking buses (but not metro). As the egress distance to the workplace increases, the metro becomes less appealing than cars. Mixed land use encourages people to walk or take buses instead of driving. Older people prefer riding buses and walking to driving, and female respondents tend to prefer walking, cycling, and riding the metro to driving compared to male respondents. These findings contribute to understanding the behavior of people who are familiar with public transportation and how to encourage them to switch from driving cars to alternative transport modes.
\end{abstract}

Keywords: Vehicle ownership, commuting behavior, city center residents, transitoriented development (TOD)

\section{Article history:}

Received: April 23, 2019

Received in revised form: November 2, 2020

Accepted: November 3, 2020

Available online: January 19, 2021

Copyright 2021 Tao Chen, Haixiao Pan \& Yanbo Ge

http://dx.doi.org/10.5198/jtlu.2021.1606

ISSN: 1938-7849 | Licensed under the Creative Commons Attribution - Noncommercial License 4.0

The Journal of Transport and Land Use is the official journal of the World Society for Transport and Land Use (WSTLUR) and is published and sponsored by the University of Minnesota Center for Transportation Studies. 


\section{Introduction}

China is undergoing rapid urbanization and motorization. This process has heavily affected the traditional urban structure in the form of an increase in the employment density in central business districts as well as the emergence of multiple suburban employment centers. In addition to a rapid increase in the car ownership rate, the clash between the old city structure and new transportation behaviors has resulted in the least-desired byproducts of modernization: congestion, air pollution, and an increase in $\mathrm{CO} 2$ emissions. The relevant authorities and planners wish to solve such problems by constructing public transportation-oriented metropolitan spatial structures and promoting sustainable development, and dozens of cities in China have constructed or are planning to construct a metro system. Starting in the early 1990s, in each decade, metro systems have expanded faster than in the previous one, with a yearly increase of $83 \mathrm{~km}$ and $371 \mathrm{~km}$ in the late 2000s and early 2010s, respectively. At the beginning of 2010, the total length of urban railways was $930 \mathrm{~km}$, but by the end of 2017, the number reached $4,570 \mathrm{~km}$. It is predicted that by the end of 2020 , the total length will be $7,300 \mathrm{~km}$ at the minimum (FORWARD, 2018).

However, despite the rapid growth of the metro system, private car ownership continues to grow, worsening congestion and pollution problems in Chinese cities, especially in city centers, along with many other problems, such as the lack of parking areas. Aware of such problems, city governments have started to implement the regulation of car ownership and usage, the former mainly through restrictions on license acquisition and the latter mainly through license usage control and limiting certain licenses from being used in certain areas during certain time periods. At times, such efforts might be countered by drivers purchasing more cars.

As further methods to reduce car use, as well as connect the expanding suburban areas to the city center, the metro system was implemented. This system, like the Western metro system it learned from, also mainly focuses on connecting the residents in suburban areas to their workplaces in the city center, which results long distance between stations. However, it is worth noting that, unlike the metropolis of many developed countries, where few people live in the city center, the expanding Chinese megacities' centers are usually heavily populated. This has an evident impact on the commuting patterns of Chinese megacities. As expanding metropolises, a large portion of these cities' populations consists of migrants from other parts of China; the majority of them, like their counterparts in developed countries, usually live in suburban areas of the city due to the relatively low real estate prices and work in the city center where large corporations are located or other parts of suburban areas. However, in this study, we focus on another group of people - those who have lived in Shanghai for many years and are likely already to be familiar with public transportation in Shanghai. Some of them work in large corporations or other institutions, such as schools or hospitals in the city center, and others work in companies that have moved to suburban areas of the city to reduce expenses, which require them to commute in a different or even a reversed pattern. They usually do not earn very high incomes but have no housing loans and enjoy relatively easy access to the public transportation system. These people are the subject of this study, the original center dwellers of a metropolis. They are not necessarily the indigenous people who lived there for generations, but they did move there many years, even decades ago, before the drastic urbanization took place. This phenomenon has rarely been researched in the past, but it does exist in Shanghai and many other Chinese cities and deserves some attention to their commuting and mobilization patterns, especially their choice of purchasing a vehicle and their commuting mode when public transportation is relatively easy to access.

However, despite the differences in people's commuting environments, it is ultimately their decision whether to buy a car and use it to commute or not. In certain situations, there is no alternative, but in most cases, due to the widespread availability of public transportation networks, the commuting 
mode is a choice for which the participants must weigh each option's benefits and disadvantages. Further, in addition to objective factors, subjective factors also play an important role in decision-making; in some cases, it is the deciding factor in the commuting decision. Unlike objective factors, subjective factors are more chaotic and harder to predict, but nonetheless, "I don't like it" is a reason we cannot ignore.

In this study, we will delve into the subjects mentioned above to see how people's lives in the city center and their preferences shape the pattern of their commuting choices and how planners and relevant authorities may influence this pattern for the greater good.

\section{$2 \quad$ Literature review}

Undoubtedly, many aspects examined in this study have been considered by many scholars, and their wisdom can help this research tremendously. The review will follow each aspect to the articles that concern them: How do residents choose to purchase a car for commuting or not? How does the built environment and other spatial characteristics in a high-density urban area affect residents' commuting patterns? How does demographic composition affect these patterns? What is the difference between the center dwellers and those of suburban dwellers in these patterns? Furthermore, how do these patterns affect their decisions on car purchasing and commuting?

\subsection{Factors that impact on car purchase decisions}

What changes a family's decision and prompt them to buy a car? Some scholars believe the cause is the built environment (Ding, Wang, Tang, Mishra, \& Liu, 2018), while others believe it is attitude (He \& Thøgersen,2017), but whatever has an impact on people's decisions, it is not a discrete one, rather a continuous process marked by the transition of life stages (Clark, Lyons, \& Chatterjee, 2016). No doubt, household income also plays a large role in car ownership, with commuters responding to income rise and fall in different ways (Dargay, 2001).

\subsection{Impact of the built environment and spatial location on commuting modes in high- density urban areas}

One of the most prominent factors affecting commuting mode is the built environment, especially when located in a densely populated and built-up area. Ewing and Cervero (2010) conducted a meta-analysis on the built environment and travel studies, finding that vehicle miles traveled (VMT) are strongly related to destination accessibility and street network design variables; walking and public transportation are most related to land use diversity and access to a public transportation network. Another study used travel and environment data from 15 diverse U.S. regions to build a model with more external validity than any to date (Ewing et al., 2015) in predicting car trips, walking trips, bike trips, transit trips and VMT. A large-scale study in Mexico involving the largest 100 urban areas and 2.5 million commuters found that, in population centers where jobs are spatially concentrated, people drive less. However, it is highly dependent on the built environment: there is less driving in areas where better public transportation exists and more driving in car-friendly urban environments (Guerra, Caudillo, Monkkonen, Montejano, 2018). Nevertheless, this does not necessarily mean that public transportation will be faster in an area better supported by public transit: In a city with a dense public transportation system and high occurrence of congestion such as Beijing, the overall commuting time by public transportation is still longer than that by car (Zhang \& Man, 2015). A study in Zurich, Switzerland, spanning 20 years found that the spatial factors are highly interdependent, and changes in these factors usually happen simultaneously instead of successively. However, among these changes, a change in work or education 
location leads to a longer commuting distance, whereas changes in residential location might reduce it (Beige \& Axhausen, 2017). A study in Chicago also found that, despite the importance of income, workplace location plays a greater role in commuting mode choice (Hu \& Schneider, 2017).

However, the relocation of workplaces will not result in corresponding household relocations and commuting distances would greatly increase should workplaces be relocated from the city center to suburban areas (Vale, 2013). Another survey in Kunming, China, focusing on the relocation of workplaces by government also found that as jobs are relocated to new towns in the urban periphery in an attempt to decentralize a city, the actual travel pattern changes according to household location and new travel time and likely shifts from more sustainable modes to private cars (Yang \& Day, 2017). Confronted with this problem, some scholars have attempted to establish a model to explore the possibility of a well-designed city that could minimize the use of cars. Model simulations have shown that a reduction in commuting distance paradoxically leads to more cars being driven in the city and the metro system, designed for long-distance travel, becoming obsolete (Korsu \& Néchet, 2017). This result seems to be rather strange for Western countries, especially the U.S., but fits the commuting patterns in developing countries such as Tanzania (Bwire \& Zengo, 2020). Shanghai has a similar pattern; a research study in a suburban area indicated that driving accounts for $58.8 \%$ of the commuting travel that requires less than 0.5 hour, and $69.8 \%$ of the travel that requires 0.5 hour to 1 hour, but for the travel that requires more than 1 hour, driving accounts for only $28.6 \%$, while metro use rises from $9.8 \%$ and $16.3 \%$ to $71.4 \%$ of the total travel (Zhang, Chen, \& Li, 2018). Although shorter travel time does not necessarily mean shorter distances in the case of driving, longer travel time certainly indicates a longer distance, especially when switched to metro. This is likely because long-distance commuting at rush hour faces severe congestion, but governmental subsidies could also play a role here; the cost difference between private cars and metro becomes huge when the travel distance is long enough. As a result, riding the metro becomes more popular for long-distance commuting than driving.

\subsection{Impact of demographic composition}

Another factor heavily influencing the commuting mode is the demographic composition of commuters. As one of the fastest-changing countries globally, China is perfect for comparing people's travel behavior changes in a relatively short period in response to changes in their household income. A study in Nanjing City has determined that not only has the use of private cars and public transportation increased drastically in merely three years at the expense of non-motorized modes, but the gap in mode choices between people from different built-up environments and with different household incomes has also expanded rapidly (Feng \& Dijst, 2017).

Different behaviors between genders are also a universal phenomenon across the world. In the early 1990s, gender still played a defining role in the mobility of the U.S., as married women usually had shorter commutes than married men (Johnston-Anumonwo, 1992). Revisiting the topic more than ten years later reveals that the size of this gap has decreased but persists in the country (Crane, 2007).

\subsection{Different patterns of suburban and urban center commuting}

As mentioned above, the differences in and interactions of commuting modes involving the city center area should be described based on the different types of commuters: those who live and work in the city center, those who live in suburban areas and work in the city center and those who live in the city center and work in suburban areas.

People who live and work in the city center usually either rent or own an apartment. Due to the instability of the Chinese renting market both price- and consistency-wise (Xu, Zhang, Zheng, \& Zhu, 
2018), the number of renters is highly fluid and temporary. Those who own an apartment have either bought it sometime in the past or have acquired it as an inheritance from their family, through governmental relocation, or through company welfare. Even those who bought their apartment may have paid a drastically different price at a different time. The population with a much higher income, not included in this study, usually comprises middle-class households, who tend to buy a housing unit in a nearby suburban area instead of an apartment in the city center and commute for relatively short distances by private car if they commute at all (Dai, Zhou, \& Ye, 2016).

People who live in suburban areas and work in the city center comprise most of the commuting population in an expanding metropolis; they are usually people who have migrated to the metropolis for better opportunities. They can only afford apartments in suburban areas but work at major companies in the city center (Xiaopei, 1994). They comprise the majority of a city's commuters and the majority of those utilizing the metro system but also own a substantial number of cars, although their commuting behavior varies under different conditions (Shen, Chen, \& Pan, 2016).

The last scenario, the commuting pattern of people who live in the city center and work in suburban areas, has rarely been studied in the literature, as center dwellers usually comprise a shrinking group, if such even exists and mainly are mentioned in the past tense, as the "original pattern of the city" (Morozova, Stepanenkova, \& Malashkin, 2016). Even in Chinese metropolises such as Beijing, center dwellers have already largely moved to suburban areas. However, in Shanghai, there are still a great number of people who have lived in the city center for decades and still live there; these comprise the respondents of this study, from whom we aimed to discover people's commuting choices when living in an environment with a dense and well-established public transportation system.

\subsection{Attitudes on travel modes}

People's environment and economic capacity may push them toward certain travel modes, but which mode someone will take is ultimately an individual's decision-personal preference plays an important role in this phase. Sometimes, researchers will use "happiness" to determine people's overall preference toward a travel mode; whether someone's attitude is "happy" or "unhappy" strongly influences the choice of commuting mode (Kamruzzaman, Shatu, Hine, \& Turrell, 2015). Some scholars have discovered that a dedicated shuttle (i.e., company bus) results in the most happiness, followed by a personal bicycle and walking. Public bicycles, the metro, and private cars are similar as regards happiness, while a public bus results in the most unhappiness (Zhu \& Fan, 2018). This may be attributed to the crowding, congestion, and overall commuting time, as it has been found that people with a longer commuting time report systematically lower subjective well-being (Stutzer \& Frey, 2008).

However, commute time is not entirely bad: Most people would like to reduce their commuting time instead of eliminating it and a few even wish it were a little longer (Redmond \& Mokhtarian, 2001). Wishing for more commuting time is likely a psychological demand for a private and protected time of solitude, especially in a smaller town and/or in cases of commuting on foot or by bicycle (Friman, Fujii, \& Ettema, 2013). The theory behind this phenomenon is called planned behavior; it states that the intention to perform the behavior can be predicted through the attitude toward the behavior, subjective norms, and perceived behavior control (Ajzen, 1991).

In this study, we focus our attention on an aspect rarely mentioned in previous studies, the commuting behaviors of the original residents in an expanding metropolis. They live in the city center, but many work in suburban areas. They have a different, even reversed commuting pattern. How such a pattern affects their car ownership, and more importantly, their car ownership tendency in the future, is what we investigate in this study. Further, knowing the mechanism for this tendency, methods could be applied to alter the tendency to benefit society. 


\section{$3 \quad$ Research design}

\subsection{Survey areas}

Using Shanghai as an example, we conducted a survey around seven neighborhoods in the central (three neighborhoods) and suburban areas (four neighborhoods) in October 2013, as shown in Figure 1. We included several questions in the questionnaire survey to collect data on respondents' intention to use the metro as the primary commuting mode when moving to the current neighborhood, as well as their considerations for choosing commuting modes. The questionnaires were filled by a stratified, randomly selected sample of households and their members from each street block within each neighborhood, focused on several aspects that would impact on travel behavior: respondents' information, such as gender, household income, would their type of occupation require a regular commuting trip; location information, such as the population density, road density and land use diversity in their home and workplace, the distance between their home and workplace to metro station; and their attitude towards private vehicle or public transportation were recorded.

In this paper, we focus mostly on analyzing the samples from the city center, which is the shaded area in the fig. 1 , roughly compose $1.7 \%$ of the entire Shanghai Municipality $\left(114.2 \mathrm{~km}^{2}\right)$. The data concerning suburban areas were used on another paper and could be very interesting and inspiring when compared with each other. Through the questionnaire, the respondents reported their own social demographic information, their home and workplace locations, their attitude toward commuting by metro and detailed information about their commuting trips, including modes and duration.

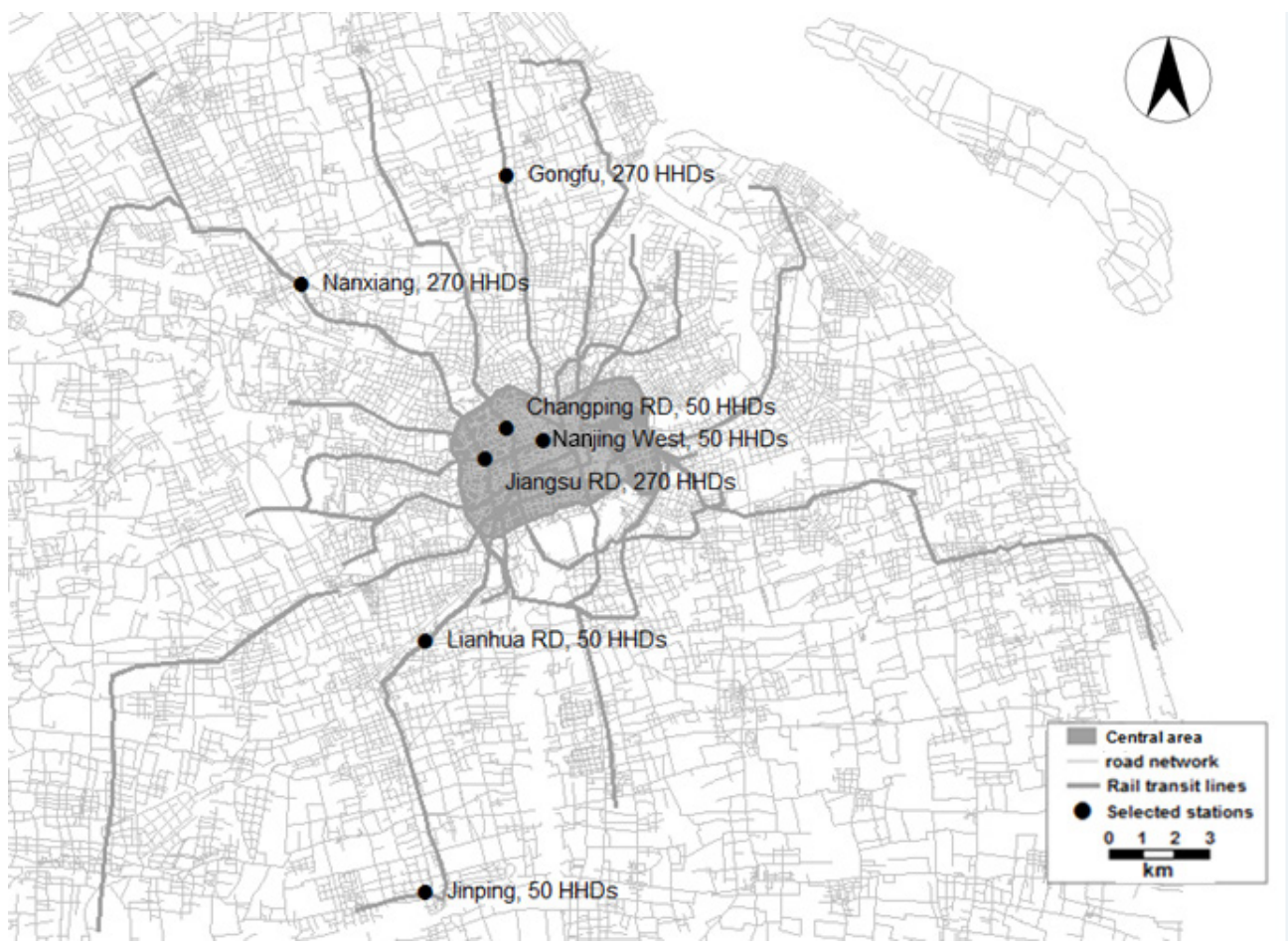

Figure 1. Location of selected stations

To recruit respondents with different forms of accessibility to metro service in each neighborhood, street blocks with different distances to metro stations were chosen for the household survey. In the city 
center, 370 households were investigated, among which 75 were within $500 \mathrm{~m}$ distance from metro stations, 130 were between $500 \mathrm{~m}$ to $800 \mathrm{~m}$, and 165 households were more than $800 \mathrm{~m}$ away. The number of valid households at this stage was 270 with 674 respondents.

\subsection{Methodology}

Based on the home and work locations obtained from the questionnaire, several variables were calculated, and the data were used in a logit model to find if these variables affect people's choice of buying a car and commuting modes. Distances were calculated based on the road network, and the variables of the land use mixture at the origin and destination were grouped into five categories: residential area, commercial area, industrial area, transportation, and open space. The percentage of each category of land use $\mathrm{Pi}(\mathrm{Pi}=\mathrm{Ai} / \mathrm{A})$, where $\mathrm{Ai} / \mathrm{A}$ refers to the percentage of a specific land use type inside a 500-meter buffer zone, was used to calculate the two variables, as shown in Equation 1:

$H=-\sum_{i=1}^{N}(P i) \ln (P i)$

The variables that were calculated for this research include: road network commuting distance (distance), distance from home location to the nearest metro station (accessdistance), distance from workplace to the nearest metro station (egressdistance), population density at the home and employment density at the workplace location (home: opopuden, workplace: demployden), road network density at the home and workplace location (home:oroadden, workplace: droadden), and mix of land use at the home and workplace location (home:omixland, workplace: dmixland). Also added to the research were household income (hhincome), apartment ownership (apartmentownership1\&2), and if they were working in the city center (centerworker).

Distances from home/workplace to the nearest metro stations are all network distances. Using these two variables to represent the convenience of metro service, we assume that people will choose the nearest station and then transfer to another line if they need to.

Population/employment density and road network density are all calculated with a radius of 500 meters around target locations. In the case of home location, it is 500 meters around each street block's center; in the case of workplace, it is 500 meters around each respondent's reported workplace location. The cost and time are the overall money and time respondents spent on their commuting trip.

Income data were used to divide respondents into five categories: RMB $0-40,000$ per year was considered poor, RMB 40,000-100,000 per year was considered low income, RMB 100,000-250,000 per year as high income, RMB 250,000-500,000 as rich, and beyond RMB 500,000 as very rich. However, in these old neighborhoods, there were only three respondents from the same family claiming to earn an income of RMB 250,000-500,000 and no one claimed an income over RMB 500,000. Also, only nine respondents from seven families fell in the poor category; together, the rich and poor only comprised a little more than $1 \%$ of total respondents. Thus, the rich and high income were aggregated into the higher income category, and poor and low income were aggregated to the lower income category. As a result, the boundary between higher and lower income was then set at RMB 100,000/year, the average yearly income for a two-job family in Shanghai.

Apartment ownership was divided into three situations: bought, rented, or other. Other included an apartment that had been provided by their companies or institute they worked in or inherited from their parents, and a similar situation when they acquired their apartment unit without buying it.

Whether respondents were working in the city center or in a suburban area were decided by their 
reported workplace, defined by whether they were within the boundary of the city center.

The variables involved in this article are listed in Table 1.

Table 1. Descriptions of variables

\begin{tabular}{|c|c|}
\hline Variables & Values and Descriptions \\
\hline attitude & $\begin{array}{l}=1 \text { if the respondent reported in the questionnaire she/he preferred metro if the commuting } \\
\text { times of metro and car were the same; } \\
=0 \text { otherwise. }\end{array}$ \\
\hline hhincome & $\begin{array}{l}=1 \text { higher income; } \\
=0 \text { lower income. }\end{array}$ \\
\hline gender & $\begin{array}{l}=1 \text { if gender is male; } \\
=0 \text { otherwise. }\end{array}$ \\
\hline occupation & $\begin{array}{l}=1 \text { if the occupation requires regular commuting trips; } \\
=0 \text { otherwise. }\end{array}$ \\
\hline distance & $\begin{array}{l}\text { Continuous variable. It is obtained by applying the shortest path analysis in the GIS package } \\
\text { after geocoding of the residential area and workplaces of the respondent. }\end{array}$ \\
\hline apartmentownership1 & $\begin{array}{l}=1 \text { if apartment was bought; } \\
=0 \text { otherwise }\end{array}$ \\
\hline apartmentownership2 & $\begin{array}{l}=1 \text { if apartment was rented; } \\
=0 \text { otherwise. }\end{array}$ \\
\hline centerworker & $\begin{array}{l}=1 \text { if working in city center; } \\
=0 \text { otherwise. }\end{array}$ \\
\hline accessdistance & $\begin{array}{l}\text { Continuous variable. In the central area, walking access distance was obtained by shortest } \\
\text { path analysis. In the suburban areas, it was based on the same analysis but on different access } \\
\text { modes. }\end{array}$ \\
\hline egressdistance & $\begin{array}{l}\text { Continuous variable. Access distance was obtained by applying the shortest path analysis by } \\
\text { walking. }\end{array}$ \\
\hline opopden & Continuous variable. The population density at home ( $10^{3}$ people per square kilometers). \\
\hline oroadden & $\begin{array}{l}\text { Continuous variable. The sum of road length divided by the area at homes (the radius is } 500 \\
\text { meters). }\end{array}$ \\
\hline omixland & Continuous variable. The mix of land use at home location. \\
\hline demployden & $\begin{array}{l}\text { Continuous variable. The employment density at workplaces ( } 103 \text { people per square kilome- } \\
\text { ters). }\end{array}$ \\
\hline droadden & $\begin{array}{l}\text { Continuous variable. The sum of road length divided by the area at workplaces (the radius is } \\
500 \text { meters). }\end{array}$ \\
\hline dmixland & Continuous variable. The mix of land use at work location. \\
\hline cost & The total daily commuting cost of a respondent. \\
\hline time & The total time a respondent spent on one-way commuting. \\
\hline
\end{tabular}

Other social demographic information for the respondents and built environment characteristics were also collected, especially several important statistics, such as the percentage of current car owners and car users, and the percentage of respondents who rented or owned apartments in these areas. 


\subsection{Results and analysis}

\subsubsection{Survey statistics and analysis}

The results show that of the 674 respondents, 77 were from outside Shanghai, which means $88.6 \%$ of the respondents were original Shanghai residents. However, even among the 77 outsiders, only 14, consisting of 8 families, had migrated to Shanghai after 2005; the other 63 could still be considered original residents, having lived in Shanghai before its rapid expansion. This means that $2.1 \%$ of the respondents were outlanders. However, originally in Shanghai does not necessarily mean that a respondent has lived there longer or owns an apartment there $-45 \%$ of respondent families lived in rented apartments, most of them were from other parts of Shanghai, and 33\% of them lived in apartments they bought themselves. The 14 respondents who cannot be considered original residents were subsequently removed. A further look into where respondents work provided more information. Among the 660 respondents, 188 did not provide their workplace information, meaning they may either be self-employed or already retired. The survey data showed that $43 \%$ of them were more than 60 years old. One hundred eightyeight respondents worked outside the city center, whereas 286 commuted within the city center, which means that nearly $40 \%$ of the commuting populations in these areas are commuting in a reverse pattern-from the city center to the outskirts in the morning and returning in the evening.

Fifty-seven percent of these reverse commuters had a relatively lower income, $43 \%$ of them a relatively higher income, $77 \%$ of them did not own a car, and $85 \%$ of them commuted with alternative means instead of cars. Sixty-two percent and 38\% of the respondents working within the city center were considered to be from a relatively lower-income population and from a relatively higher-income population, respectively. Eighty-one percent of them did not own a car and $87 \%$ of them commuted by alternative means instead of cars.

The results are interesting: People working in sub-centers or suburban areas exhibit an average car ownership rate and a higher-than-average proportion of them commute by car, whereas people working in the city center exhibit a lower-than-average car ownership rate and an average proportion of them commute by car. This indicates that a family member who works in the city center is less likely to commute by car when they purchase one, as they leave the car with their family members who may not work in the city center.

Those working in the city center earn a relatively lower income compared to those working in subcenters or suburban areas. This is likely because the majority of those working in the city center do not work in commercial areas, such as Lujiazui. Rather, their workplaces are hospitals, schools, and other facilities or service jobs, which do not offer a very high salary, whereas sub-center and suburban workplaces usually consist of companies and factories.

The valid respondents comprise 262 families; among them, 53 families own a car-approximately $20 \%$ of all families. But if a family owns a car, then that car would be almost certainly used for daily commuting.

Combining car ownership data with apartment ownership and family income data yields some interesting results. Among 33\% of families who have bought apartments themselves, 31\% have also bought a car. Additionally, nearly $60 \%$ of those who have bought apartments are ranked as lowerincome families. In comparison, among the $45 \%$ of respondent families who rent an apartment, $19 \%$ have bought a car, and $51 \%$ are ranked as lower-income families. The remaining $22 \%$ are those who live in an apartment without having paid for it. They either inherited the apartment, received it as compensation for governmental relocation, or received it from their state-owned employers as welfare decades ago. Only 3\% of them have bought a car, and 52\% are ranked in the lower-income category. 
It is quite evident that families who can afford an apartment are more likely to purchase a car than those who rent. However, the income data seem to portray the opposite story, with more lower-income families being among those who have bought an apartment. Only $11 \%$ of those who bought an apartment bought it after 2005 and $4 \%$ after 2010 . This added to the fact that real estate prices have been rising rapidly in recent years implies that the "bought vs. rent" distinction should not be considered equivalent to "rich vs. poor," but rather a matter of insight into the tendency of real estate prices and some good fortune as well. Nevertheless, the absence of a pressing need to buy an apartment results in more car purchases.

\subsubsection{Analyzing car ownership with a binary logit model}

In the second phase, a binary logit model was used on the individual level to determine the impact of personal traits on the decision to buy a car. The results showed that respondents' attitudes toward metro commuting, their household income, ownership of the apartment they live in, the population density of the residential area, and the distance of each family member's workplace to the nearest metro stations significantly influence their decision to own a car. The results are summarized below in Table 2 . For those who prefer the metro and would choose the metro given that the travel time by metro and car are the same, the probability of buying a car is lower than for those who prefer a car. Those earning a higher income are more likely to own a car than those earning a lower income. Those who bought their apartment have a higher probability of owning a car compared to those who rent an apartment; yet, even those who rent an apartment have a higher probability of owning a car than those who own an apartment that they did not buy. The population density of the residential area has a slight negative impact on car ownership; that is, a crowded neighborhood may dissuade people from buying a car for lack of parking areas and similar inconveniences. The employment densities at workplaces slightly encourage car purchase, likely because high-job-density areas in Shanghai usually try to provide a more car-friendly environment. Households with one or more family members working in the vicinity of metro stations have a lower probability of owning a car compared to those who work far from metro stations.

The number of years a household has lived in its current location does not correlate with owning a car. The distance from the residential area to the nearest metro station does not significantly influence people's decision to purchase a car. This could be the result of one or several factors, one of which is that, since in the city center the distance between metro stations is approximately $1.5 \mathrm{~km}$, walking to the station is relatively convenient. The other possible factor is that, because of the higher-value real estate, people with a higher income can afford properties around metro stations and tend to purchase their estate there, and they also have a higher probability of buying a car, which may negate the effect of distance on car ownership probability.

Whether a respondent works in the city center or in suburban areas does not influence car ownership, nor are the built environment variables of the residential area significant. This could be the result of the low variation of these variables due to the homogeneity of the built environment in the city center. The built environment of the workplace does not influence people's choice to own a car, nor does the time and monetary cost for commuting affect a respondent's family decision to own a car, either. These results indicate that people's decisions regarding purchasing a car are influenced more by their social demographic characteristics and their attitude toward public transportation and less by urban land use in the dense city center. 
Table 2. Binary logit model results

\begin{tabular}{llllll}
\hline & B & Std. Error & Wals & Sig & Exp(B) \\
\hline years & .005 & .014 & .108 & .742 & 1.005 \\
\hline hhincome & .028 & .004 & 57.649 & $.000^{* * *}$ & 1.029 \\
\hline attitude & -1.628 & .424 & 14.762 & $.000^{* * *}$ & .196 \\
\hline apartmentownership1 & 4.753 & .795 & 35.719 & $.000^{* * *}$ & 115.914 \\
\hline apartmentownership2 & 3.117 & .756 & 16.982 & $.000^{* * *}$ & 22.569 \\
\hline age & .050 & .079 & .394 & .530 & 1.051 \\
\hline age2 & -.009 & .010 & .712 & .399 & .991 \\
\hline accessdistance & -1.330 & .890 & 2.232 & .135 & .264 \\
\hline egressdistance & 1.028 & .322 & 10.209 & $.001^{* * *}$ & 2.797 \\
centerworker & -.397 & .525 & .570 & .450 & .673 \\
\hline opopden &. .132 & .062 & 4.605 & $.032^{* *}$ & .876 \\
demployden & .056 & .034 & 2.711 & $.100^{*}$ & 1.058 \\
\hline omixland & .461 & 1.327 & .121 & .728 & 1.585 \\
\hline dmixland & -.462 & .593 & .607 & .436 & .630 \\
\hline time & -.006 & .010 & .406 & .524 & .994 \\
\hline cost & .006 & .058 & .009 & .923 & 1.006 \\
constant & -3.565 & 2.642 & 1.821 & .177 & .028 \\
\hline
\end{tabular}

Figure 2 below shows the probability of owning a car based on the distance from one's workplace to the metro and is divided into low- and high-income groups. The central line is the predicted probability, and the shaded areas are the confidence intervals. The graphs are based on the dummy variable for attitude on transit, with 0 representing preference for a car and 1 representing a preference for the metro. At a distance from home to metro station of $600 \mathrm{~m}$, the low-income group has a lower probability of owning a car compared to the high-income group. The group with attitude equal to 0 has a higher probability of owning a car. This probability is mostly constant for all distances from the workplace to the metro. At an access distance of 1,500 m, the higher-income group has a higher probability of owning a car compared to the lower-income group regardless of their attitude level. However, those with an attitude equal to 0 still have a higher probability of owning a car compared to those with an attitude equal to 1 . For the high-income group, the common scenario is true: those living farther from a metro station have a higher probability of owning a car compared to those living closer. In comparison, low-income people living 1,500 $\mathrm{m}$ from metro station shows a much lower level of car ownership than those living only $600 \mathrm{~m}$ from metro station. Moreover, an attitude of preference for car results in an even higher probability to own a car for the low-income group if living closer to the metro. 


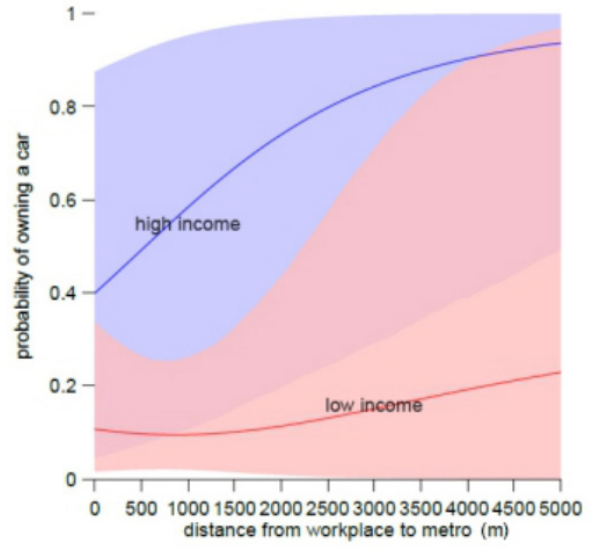

Attitude $=1$, accessdistance $=600 \mathrm{~m}(\mathrm{a})$

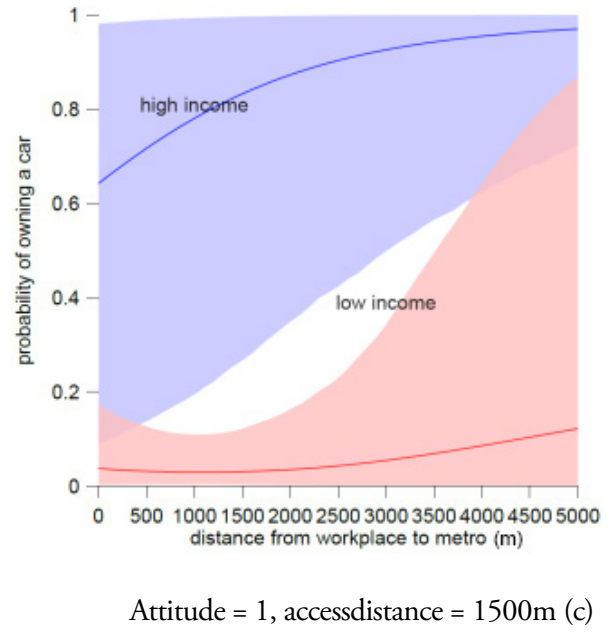

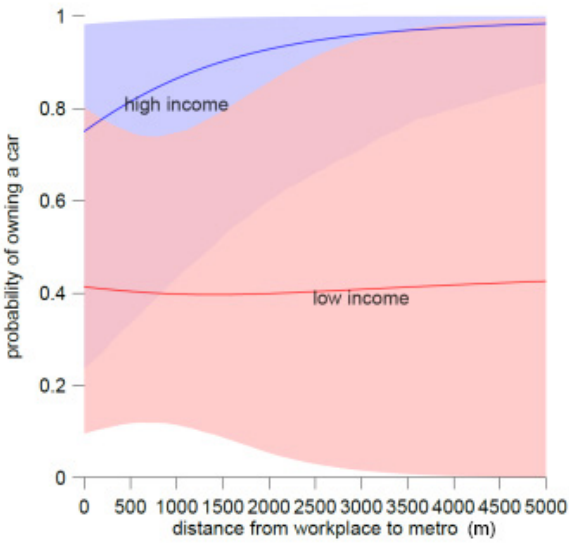

Attitude $=0$, accessdistance $=600 \mathrm{~m}(\mathrm{~b})$

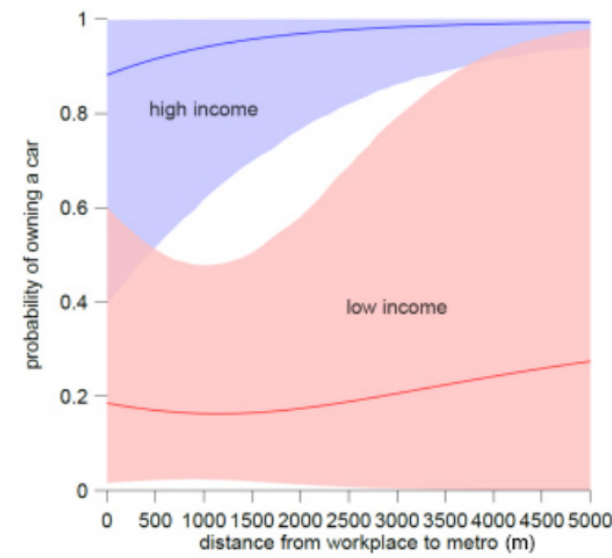

Attitude $=0$, accessdistance $=1500 \mathrm{~m}(\mathrm{~d})$

Figure 2. Probability of owning a car as influenced by attitude, income, and distance

For high-income households with an attitude of 0 (Figure 2.b \& Figure 2.d, people who choose to purchase a car when the commuting time by car or by metro are the same), the confidence interval of car ownership is narrower than that of high-income respondents with an attitude of 1 (Figure 2.a \& Figure 2.c), which indicates that attitude toward public transportation influences car ownership.

\subsubsection{Analyzing car commuting with a multinomial logit model}

Commuting preferences portray a potential car ownership tendency; hence, as a further supplement, a multinomial logistic model was applied to discover the factors influencing commuting mode choice. The result shows that people's choice of commuting by alternative modes instead of by car is also highly influenced by their attitude toward public transportation. People with a positive attitude toward public transportation tend to choose alternative modes instead of driving; therefore, should other factors remain the same, attitude becomes the deciding factor in both owning and driving a car. Household income also heavily impacts people's choice of commuting mode. Age also has a positive impact on respondents' choice of commuting by bus and metro instead of by car; likely, aged respondents usually 
work closer to where they lived before the city expansion and have habitually commuted by bus since then. The age-squared result shows that, as age further increases, the trend is reversed.

As shown by the results in Table 3, the increase of access distance from one's home to metro stations slightly encourages commuting by metro instead of by car, which may be related to the car ownership pattern. According to this pattern, when income is the same, car-preferring respondents who live closer to a metro station are more likely to purchase a car; hence, they are less likely to commute by metro if living closer to a metro station. The distance from a workplace to the metro station is overwhelmingly negatively correlated with the choice of commuting by metro instead of a car, likely because many respondents work in suburban areas, where the distance to a metro station matters. This also means that creating more workplaces in the vicinity of metro stations, or the other way around, linking suburban employment centers to the metro could help reduce car dependency, at least for people who reverse commute. The overall distance from home to workplace strongly discourages respondents from walking, cycling, or taking buses instead of driving, but the metro has a slight advantage over a car in this matter.

One of the built environment variables — the mixed land use in the working place-is significant in the mode choice model, which means that, although the built environment variables do not influence people's decision to own a car, they influence their commuting mode choice: a higher mix of land use at the workplace can encourage people to commute on foot instead of by car, whereas in residential areas, it slightly discourages people from taking the metro instead of driving. Commuting time has no effect on commuting mode choices, but commuting costs may reduce respondents' tendency to take the metro instead of driving.

The density of roads, both around the residence and the workplace, has no impact on commuting mode choices. The population density in residential areas has little effect on mode choices, but employment density at the workplace discourages people from taking buses instead of cars. Regarding gender, however, females have a higher tendency to choose walking, cycling, or the metro than males, excluding buses. The reason for this is likely the same as the one Johnston-Anumonwo found that we mentioned before: female family members usually commute a smaller distance than males, thus allowing males to commute by car if they have one (Johnston-Anumonwo, 1992). Whether one works in the city center or not has little effect on commuting mode choices, except for cycling, in which case, if someone works in the city center close to his/her home, he/she might choose to ride a bicycle or e-bike instead of driving, which means that improving the cycling environment would reduce car dependency in the city center.

Figure 3 shows the probability of using the metro based on the distance from the workplace to the metro. The central line is the predicted probability of people commuting by metro instead of by car, and the shaded areas are the confidence intervals. The lower-income group, whose attitude prefers a car, has an equal or higher probability of using a car compared to the higher-income group if its respondents' attitudes lean toward the metro. The graphs suggest the importance of attitude and how preference for a car makes a difference in both income groups and across a range of distances. The importance of attitude indicates the importance of having public opinion favor the metro, which could function as the subjective norm that impedes the behavior of using a car, and such public opinion can, and should, be promoted by policies. 

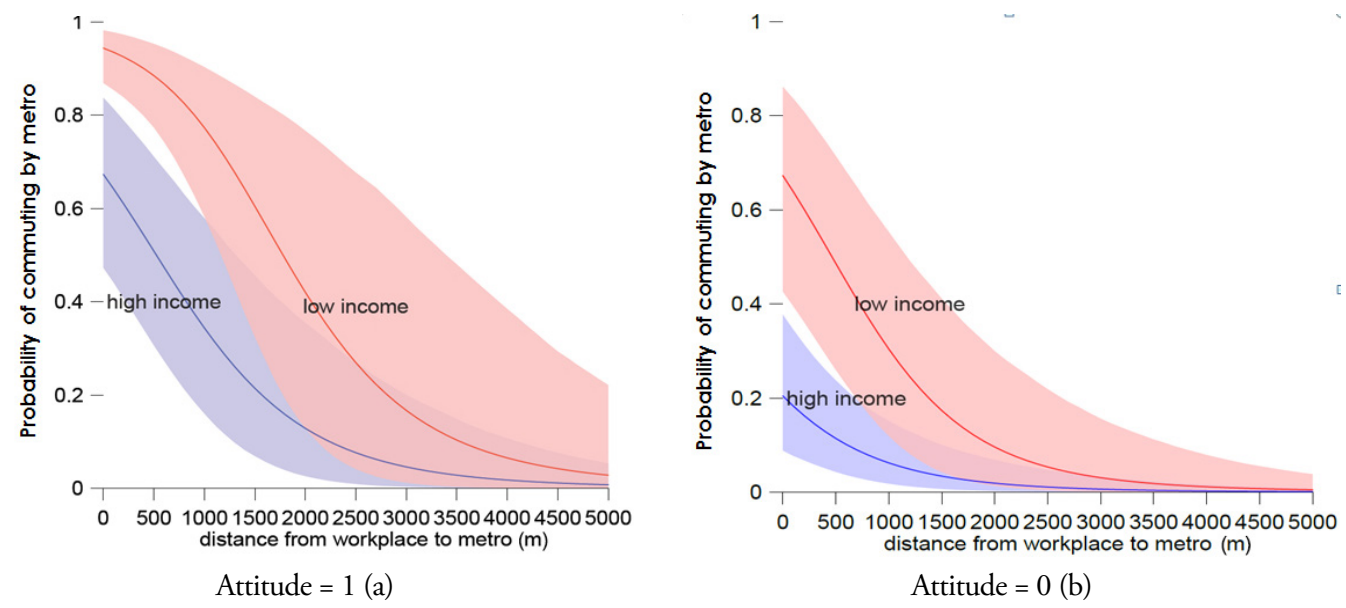

Figure 3. Probability of commuting by metro

Table 3. Multinomial logit results

\begin{tabular}{|c|c|c|c|c|c|}
\hline Variables & Estimate & Std. Error & Wald & Sig & $\operatorname{Exp}(B)$ \\
\hline intercept - walking & 6.763 & 14.431 & .220 & .639 & \\
\hline intercept - cycling & -5.346 & 3.893 & 1.885 & .170 & \\
\hline intercept - metro & -6.606 & 3.721 & 3.152 & $.076^{*}$ & \\
\hline intercept - bus & -6.284 & 3.950 & 2.531 & .112 & \\
\hline hhincome - walking & -.022 & .011 & 4.074 & $.044^{* *}$ & .978 \\
\hline hhincome - cycling & -.016 & .005 & 10.984 & $.001^{* * *}$ & .984 \\
\hline hhincome - metro & -.019 & .004 & 18.474 & $.000^{* * *}$ & .981 \\
\hline hhincome - bus & -.014 & .005 & 8.033 & $.005^{* * *}$ & .986 \\
\hline age - walking & -.186 & .209 & .785 & .376 & .831 \\
\hline age - cycling & .131 & .105 & 1.551 & .213 & 1.139 \\
\hline age - metro & .309 & .105 & 8.719 & $.003^{* * *}$ & 1.362 \\
\hline age - bus & .333 & .109 & 9.310 & $.002^{* * *}$ & 1.395 \\
\hline age $^{2}-$ walking & .032 & .030 & 1.135 & .287 & 1.032 \\
\hline age $^{2}-$ cycling & -.015 & .014 & 1.107 & .293 & .985 \\
\hline age $^{2}-$ metro & -.041 & .014 & 8.754 & $.003^{* * *}$ & .960 \\
\hline age $^{2}-$ bus & -.033 & .014 & 5.442 & $.020^{* *}$ & .967 \\
\hline accessdistance - walking & 1.358 & 2.393 & .322 & .570 & 3.890 \\
\hline accessdistance - cycling & 1.211 & 1.266 & .915 & .339 & 3.357 \\
\hline accessdistance - metro & 3.041 & 1.144 & 7.063 & $.008^{* * *}$ & 20.925 \\
\hline accessdistance - bus & .405 & 1.254 & .104 & .747 & 1.499 \\
\hline egressdistance - walking & -1.265 & 1.594 & .630 & .427 & .282 \\
\hline egressdistance - cycling & -.244 & .442 & .306 & .580 & .783 \\
\hline egressdistance - metro & -1.959 & .414 & 22.394 & $.000^{* * *}$ & .141 \\
\hline egressdistance - bus & .587 & .513 & 1.309 & .253 & 1.798 \\
\hline distance-walking & -5.445 & 1.151 & 22.390 & $.000^{* * *}$ & .004 \\
\hline distance - cycling & -.220 & .075 & 8.510 & $.004^{* * *}$ & .803 \\
\hline distance - metro & .081 & .051 & 2.554 & .110 & 1.085 \\
\hline distance - bus & -.954 & .135 & 50.061 & $.000^{* * *}$ & .385 \\
\hline
\end{tabular}




\begin{tabular}{|c|c|c|c|c|c|}
\hline Variables & Estimate & Std. Error & Wald & Sig & $\operatorname{Exp}(B)$ \\
\hline opopden - walking & -.096 & .443 & .046 & .829 & .909 \\
\hline opopden - cycling & .057 & .082 & .485 & .486 & 1.059 \\
\hline opopden - metro & .039 & .077 & .254 & .615 & 1.039 \\
\hline opopden - bus & .100 & .081 & 1.502 & .220 & 1.105 \\
\hline demployden - walking & .109 & .141 & .607 & .436 & 1.116 \\
\hline demployden - cycling & -.087 & .051 & 2.850 & $.091^{*}$ & .917 \\
\hline demployden - metro & -.057 & .043 & 1.768 & .184 & .945 \\
\hline demployden - bus & -.161 & .055 & 8.655 & $.003^{* * *}$ & .851 \\
\hline omixland - walking & 1.635 & 3.938 & .172 & .678 & 5.130 \\
\hline omixland - cycling & -.681 & 2.067 & .109 & .742 & .506 \\
\hline omixland - metro & -3.343 & 1.604 & 4.345 & $.037^{* *}$ & .035 \\
\hline omixland - bus & .225 & 2.122 & .011 & .916 & 1.252 \\
\hline dmixland - walking & 4.148 & 2.176 & 3.635 & $.057^{*}$ & 63.303 \\
\hline dmixland - cycling & .611 & .857 & .508 & .476 & 1.842 \\
\hline dmixland - metro & .147 & .802 & .033 & .855 & 1.158 \\
\hline dmixland - bus & .890 & .919 & .936 & .333 & 2.434 \\
\hline oroadden - walking & -.423 & .494 & .733 & .392 & .655 \\
\hline oroadden - cycling & -.057 & .256 & .050 & .824 & .944 \\
\hline oroadden - metro & .065 & .235 & .076 & .782 & 1.067 \\
\hline oroadden - bus & .064 & .257 & .062 & .804 & 1.066 \\
\hline droadden - walking & -.278 & .234 & 1.412 & .235 & .757 \\
\hline droadden - cycling & .135 & .114 & 1.401 & .237 & 1.145 \\
\hline droadden - metro & .052 & .105 & .248 & .619 & 1.054 \\
\hline droadden - bus & .009 & .124 & .006 & .940 & 1.009 \\
\hline commuting time - walking & .010 & .034 & .090 & .764 & 1.010 \\
\hline commuting time - cycling & .001 & .014 & .009 & .924 & 1.001 \\
\hline commuting time - metro & .019 & .012 & 2.476 & .116 & 1.019 \\
\hline commuting time - bus & -.004 & .014 & .073 & .788 & .996 \\
\hline commuting cost - walking & -.569 & .452 & 1.582 & .208 & .566 \\
\hline commuting cost - cycling & -.121 & .067 & 3.294 & $.070^{*}$ & .886 \\
\hline commuting cost - metro & -.143 & .057 & 6.315 & $.012^{* *}$ & .867 \\
\hline commuting cost - bus & -.085 & .060 & 2.031 & .154 & .919 \\
\hline attitude - walking & -3.865 & 1.447 & 7.133 & $.008^{* * *}$ & .021 \\
\hline attitude - cycling & -2.206 & .632 & 12.163 & $.000^{* * *}$ & .110 \\
\hline attitude - metro & -3.123 & .546 & 32.681 & $.000^{* * *}$ & .044 \\
\hline attitude - bus & -2.117 & .620 & 11.644 & $.001^{* * *}$ & .120 \\
\hline gender - walking & 2.858 & 1.152 & 6.153 & $.013^{* *}$ & 17.425 \\
\hline gender - cycling & 1.718 & .523 & 10.775 & $.001^{* * *}$ & 5.572 \\
\hline gender - metro & .935 & .454 & 4.245 & $.039^{* *}$ & 2.548 \\
\hline gender - bus & .289 & .530 & .297 & .586 & 1.335 \\
\hline centerworker - walking & -14.207 & .000 & . & . & .000 \\
\hline centerworker - cycling & 1.360 & .767 & 3.146 & $.076^{*}$ & 3.895 \\
\hline centerworker - metro & .663 & .714 & .862 & .353 & 1.940 \\
\hline centerworker - bus & 1.299 & .813 & 2.549 & .110 & 3.664 \\
\hline
\end{tabular}




\subsubsection{Comparing city center with suburban areas}

As mentioned in section 3.1, the survey that provided data for this paper was done in seven neighborhoods, and only the data of the three that were located in the city center were used in this paper. The other four data sets from suburban areas that were not covered in this study were individually researched by our team (Shen et al., 2016), and the findings were quite interesting when compared to those of the city center. In the suburban areas, approximately $33 \%$ of households in the vicinity of the metro (on average $1.9 \mathrm{~km}$ from household to metro stations and $2.43 \mathrm{~km}$ from workplace to metro stations, which are much farther than the $1.5 \mathrm{~km}$ distance between metro stations in the city center) own one or more cars. Households farther away tend to rely less on public transportation and more on cars. The percentage of car ownership is higher than the $20 \%$ in the city center, and $20 \%-24 \%$ of commutes in these suburban areas near the metro were conducted by car.

However, due to the greater distances of suburban areas, the distance to metro stations has a much higher impact on commuting choices: In neighborhoods near metro stations, $40 \%$ of commuting trips are by metro, whereas in neighborhoods far away from metro stations, only $9 \%$ of commuting trips are by metro. This, in turn, confirms the hypothesis that the reason the distance from households to the metro in the city center has little effect on commuting choices is that station spacing is quite small in the city center. The distance from workplace to the nearest metro station affects the commuting choices of both city-center and suburban residents, which indicates that a considerable portion of both groups of residents work in suburban areas. Such different patterns between the city center and suburban areas in turn justified the decision to study these two categories separately.

\section{$4 \quad$ Discussion and conclusion}

\subsection{Discussion}

The results of this study reinforce previous studies' findings of people's choice based on household income and the mixed built environment in workplaces and different commuting tactics employed by male and female family members, as well as the effect of distance from their workplace to the metro station. However, the study on the Shanghai city center also finds results such as the following: aged people prefer buses over cars, commuting distance makes people choose cars over buses but not the metro, and the distance from home to the metro station does not affect people's choice of owning and commuting with a car in a city center with a dense metro network.

In addition to each factor's influence, some results are due to the interaction of different factors, such as the higher-income group being more sensitive to a distance increase from the home or workplace to the metro station and the overall lesser impact of the home to metro distance compared to the work to metro distance in the city center. The lower-income groups who prefer cars and live closer to a metro station have a higher probability of owning cars than those with the same preference but living farther away from metro stations. This counterintuitive result may indicate that because real estate prices have risen extremely fast in recent years, people with similar incomes but who decide to buy an apartment at different times will result in a large difference both in their disposable household income and their consumption behavior related to their perceived property value.

Considering the demand for more sustainable transportation in metropolises, the factors that result in more of such commuting modes instead of private cars should be promoted. Nevertheless, the most evident factor, household income, cannot be controlled, which leaves several aspects open for governmental influence. Among these, the distance from home and workplace to metro station depends on the density of the metro system and cannot be improved overnight; gender and age are also population 
traits that cannot be affected by planners, so what remains to be worked on are the local built environment and people's attitudes.

In Shanghai, many commercial centers have been built and continue being built across the entire city, offering recreational facilities, catering, and shopping services. They are usually located either near job centers or residential areas, greatly reducing travel demand other than commuting across the city. However, it is less effective in reducing commuting trips, especially among higher-income groups (Zhao, Lü, \& deRoo, 2011; Zhang, Zhou, \& Zhang, 2017; Jiangping, Chun, Xiaojian, Wei, \& Peng, 2014), but new employment centers located near metro stations would reduce car dependency, which was never taken into consideration in the past in Shanghai.

People's attitudes, by contrast, are in a state of flux and in many ways prone to influence, especially in the case of central areas, where different commuting options correspond to similar travel times and, thus, have similar weights when no preference has been included. As mentioned above, the realization of any prospection is influenced by people's personal attitudes, subjective norms, and perceived behavior control.

Attitude is a more personal aspect, shaped by personality and the environment one grows up in, and is difficult, if not impossible, to control.

A subjective norm, by contrast, is the product of collective society values; hence, promoting the desired commuting mode as a healthy, fashionable, and responsible mode, as well as discouraging the use of undesired modes on the basis of being wasteful, selfish, and undesirable, is possible. Should society adopt such values, this will be a powerful barrier that discourages people from choosing private cars over other modes. However, for these values to be adopted, people must be aware of the wellbeing of the society other than their own, which requires years of education, especially for younger generations.

Compared to subjective norms, perceived behavior control can be influenced more directly and easily by raising the barrier and cost of driving while simultaneously making alternative commuting modes convenient and comfortable. Shanghai already has a full set of regulations on private car control, which need to be constantly reviewed and reassessed regarding which more effective efforts should be made (Ben-Dor, Ben-Elia, \& Benenson, 2018; Kobayashi \& Do, 2005). As the population density of residential areas discourages people from using cars, encouraging bicycle use by improving cycling infrastructure helps.

Ultimately, people will likely still be drawn to cars for their convenience, and the stakeholders of automobile-related industries will still be striving to promote driving. What is needed is not only planning and executing but a prolonged struggle between immediate interests and the greater good, which means that planners and various government agencies should take action now, in hopes of better results generations later.

\subsection{Conclusion}

In this study, we conducted a household travel survey in three neighborhoods in the central area of Shanghai around metro stations to understand the motorization pattern of the original residents of the city center. The results showed that the surveyed original residents of Shanghai have a slightly lower car ownership rate than suburban area residents, but almost all the car-owning families have one of their members commuting by car. Also, $40 \%$ of all their commuting is in a reversed pattern, which metro planning should have taken into consideration. Further, delving into people's behaviors, we find that several factors significantly influence respondents' choice of owning cars: the distance of each family member's workplace to the nearest metro stations, household income, and respondents' attitude toward metro commuting. In contrast, the distance from the residential area to the metro station does not 
significantly influence the decision to own a car. In an additional analysis using an interaction term in which both the high- and low-income group variable was multiplied by the access and egress distance, the results show that the high-income group is more likely to buy cars when the distance from home to the metro increases. This likelihood becomes more significant when the distance from the workplace to the metro increases, whereas the low-income group has the opposite tendency: Respondents in this group are more likely to buy a car when the distance from their home to the metro decreases, which is likely due to the fact that real estate prices around metro stations have risen extremely quickly in recent years, people who have similar incomes but have an apartment near a station will result in a heavy impact on their consumption behavior related to their perceived property value. A multinomial logistic model was also applied to discover the factors influencing commuting mode choice. The factors identified were the following: commuting distance, which increases car usage; egress distance to the workplace, which reduces metro use; age, which increases bus riding; mixed land use, which increases walking and taking the bus; and gender.

Based on the findings of these factors, the theory of planned behavior was invoked to explore the best possible approach for promoting public transportation. Other more specific suggestions were also given; for example, new employment centers should not be located too far from the city center and should be connected to the metro as well, to prevent people whose home provides easy access to the metro from switching to driving. Also, the current transport system in Shanghai does not fit well with commuting within the city center, as trunk roads throughout the city lack support for bicycles and pedestrians, but walking is more favorable than driving in a more mixed workplace and cycling is slightly more favorable than driving if working in the city center. TOD should not just have residential clusters around metro stations; rather, it should supplement the surrounding urban amenities, and connect the employment elements citywide into the metro network, to fulfill its full potential.

\section{Acknowledgements}

This work was supported by a grant from the National Science Foundation of China (Grant Number: 51778431). We are also very grateful to the anonymous reviewers for providing constructive suggestions that improve our work tremendously. and to the editors who help on the problems we have been encountered.

\section{Appendix}

Appendix A: Research Materials available at https://www.jtlu.org/index.php/jtlu/article/ view/1606. 


\section{References}

Ajzen, I. (1991). The theory of planned behavior. Organizational Behavior and Human Decision Processes, 50(2), 179-211.

Beige, S., \& Axhausen, K. W. (2017). The dynamics of commuting over the life course: Swiss experiences. Transportation Research Part A: Policy and Practice, 104, 179-194.

Ben-Dor, G., Ben-Elia, E., \& Benenson, I. (2018). Assessing the impacts of dedicated bus lanes on urban traffic congestion and modal split with an agent-based model. Procedia Computer Science, 130, 824-829.

Bwire, H., \& Zengo, E. (2020). Comparison of efficiency between public and private transport modes using excess commuting: An experience in Dar es Salaam. Journal of Transport Geography, 82, 102616.

Clark, B., Lyons, G., \& Chatterjee, K. (2016). Understanding the process that gives rise to household car ownership level changes. Journal of Transport Geography, 55, 110-120.

Crane, R. (2007). Is there a quiet revolution in women's travel? Revisiting the gender gap in commuting. Journal of the American Planning Association, 7(3), 298-316.

Dai, D., Zhou, C., \& Ye, C. (2016). Spatial-temporal characteristics and factors influencing commuting activities of middle-class residents in Guangzhou City, China. Chinese Geographical Science, 26(3), 410-428.

Dargay, J. M. (2001). The effect of income on car ownership: Evidence of asymmetry. Transportation Research Part A: Policy and Practice, 35(9), 807-821.

Ding, C., Wang, Y., Tang, T., Mishra, S., Liu, C. (2018). Joint analysis of the spatial impacts of built environment on car ownership and travel mode choice. Transportation Research Part D: Transport and Environment, 60, 28-40.

FORWARD Business Information Co. (n.d.) Report of market demand and investment strategy planning analysis on China urban rail transit information industry (2018-2023).

Ewing, R., \& Cervero, R. (2010). Travel and the built environment, a meta-analysis. Journal of the American Planning Association, 76(3), 265-294.

Ewing, R., Tian, G., Goates, J. P., Zhang, M., Greenwald, M. J., Joyce, A., ... Greene, W. (2015). Varying influences of the built environment on household travel in 15 diverse regions of the United States. Urban Studies, 52(13), 2330-2348.

Feng, J., \& Dijst, M. (2017). Changing travel behavior in urban China: Evidence from Nanjing 20082011. Transport Policy, 53, 1-10.

Friman, M., Fujii, S., \& Ettema, D. (2013). Psychometric analysis of the satisfaction with travel scale. Transportation Research Part A: Policy and Practice, 48, 132-145.

Guerra, E., Caudillo, C., Monkkonen, P., \& Montejano, J. (2018). Urban form, transit supply, and travel behavior in Latin America: Evidence from Mexico's 100 largest urban areas. Transport Policy, 69, 98-105.

He, S. Y., \& Thøgersen, J. (2017). The impact of attitudes and perceptions on travel mode choice and car ownership in a Chinese megacity: The case of Guangzhou. Research in Transportation Economics, 62, 57-67.

Hu, L., \& Schneider, R. J. (2017). Different ways to get to the same workplace: How does workplace location relate to commuting by different income groups? Transport Policy, 59, 106-115.

Jiangping, Z., Chun, Z., Xiaojian, C., Wei, H., \& Peng, Y. (2014). Has the legacy of Danwei persisted in transformations? The jobs-housing balance and commuting efficiency in Xi'an. Journal of Transport Geography, 40, 64-76.

Johnston-Anumonwo, I. (1992). The influence of household type on gender differences in work trip 
distance. Professional Geographer, 44(4), 161-169.

Kamruzzaman, Md., Shatu, F., Hine, J., \& Turrell, G. (2015). Commuting mode choice in transitoriented development: Disentangling the effects of competitive neighborhoods, travel attitudes, and self-selection. Transport Policy, 42, 187-196.

Kobayashi, K., \& Do, M. (2005). The informational impacts of congestion tolls upon route traffic demands. Transportation Research Part A: Policy and Practice, 39(7), 651-670.

Korsu, E., \& Néchet, F. (2017). Would fewer people drive to work in a city without excess commuting? Explorations in the Paris metropolitan area. Transportation Research Part A: Policy and Practice, 95, 259-274.

Morozova L., Stepanenkova L., \& Malashkin A. (2016). Integration of a commuter rail in the transport system of the city. In M. Blinkin \& E. Koncheva (Eds.), Transport systems of Russian cities (Transportation research, economics and policy series). Cham, Switzerland: Springer.

Redmond, L. S., \& Mokhtarian, P. L. (2001). The positive utility of the commute: Modeling ideal commute time and relative desired commute amount. Transportation, 28(2),179-205.

Shen, Q., Chen, P., \& Pan, H. (2016). Factors affecting car ownership and mode choice in rail transitsupported suburbs of a large Chinese city. Transportation Research Part A, 94, 31-44.

Stutzer, A., \& Frey, B. S. (2008). Stress that doesn't pay: The commuting paradox. Journal of Economics, $110(2), 339-366$.

Vale, D. S. (2013). Does commuting time tolerance impede sustainable urban mobility? Analyzing the impacts on commuting behavior as a result of workplace relocation to a mixed-use center in Lisbon. Journal of Transport Geography, 32, 38-48.

Xiaopei, Y. (1994). The satellite towns of metropolis Guangzhou: Evolution, inherent links with the central city and tendencies —a case study of renhe town. Chinese Geographical Science, 4(1), 55-65.

Xu, Y., Zhang, Q., Zheng, S., Zhu, G. (2018). House age, price and rent: Implications from landstructure decomposition. The Journal of Real Estate Finance and Economics, 56(2), 303-324.

Yang, X., \& Day, J. E. (2017). Commute responses to employment decentralization: Anticipated versus actual mode choice behaviors of new town employees in Kunming, China. Transportation Research Part D: Transport and Environment, 52(B), 454-470.

Zhang, C., \& Man, J. (2015). Examining job accessibility of the urban poor by urban metro and bus: A case study of Beijing. Urban Rail Transit, 1(4), 183-193.

Zhang, P., Zhou, J., \& Zhang, T. (2017). Quantifying and visualizing jobs-housing balance with big data: A case study of Shanghai. Cities, 66, 10-22.

Zhang, M., Chen, T., \& Li, J. (2018). Impact of commuting time to the metropolitan periphery population activity: A case study in Huaqiao, a typical periphery community of Shanghai. In Innovation driven and smart development: Proceedings of Annual National Planning Conference. China Association of City Planning, Urban Transportation Planning Academic Committee, pp. 3533-3544 (in Chinese).

Zhao, P., Lü, B., \& deRoo, G. (2011). Impact of the jobs-housing balance on urban commuting in Beijing in the transformation era. Journal of Transport Geography, 19(1), 59-69.

Zhu, J., \& Fan, Y. (2018). Commute happiness in Xi'an, China: Effects of commute mode, duration, and frequency. Travel Behavior and Society, 11, 43-51. 